\title{
Clinical Spectrum of Precipitating Factors of Hepatic Encephalopathy in Cirrhosis of Liver and Its Relation to Prognosis in a Tertiary Care Hospital - A Retrospective Study
}

\author{
Vinoth Kumar Sethuraman ${ }^{1}$, Kavitha Balasubramanian ${ }^{2}$ \\ ${ }^{1}$ Assistant Professor, Department of General Medicine, ${ }^{2}$ Associate Professor, Department of General Medicine, Indira Gandhi \\ Medical College and Research Institute, Puducherry-605 009, India
}

Corresponding author: Kavitha Balasubramanian, Associate Professor, General Medicine, Indira Gandhi Medical College and Research Institute, Puducherry-605 009, India

DOI: http://dx.doi.org/10.21276/ijcmsr.2019.4.2.15

How to cite this article: Vinoth Kumar Sethuraman, Kavitha Balasubramanian. Clinical spectrum of precipitating factors of hepatic encephalopathy in cirrhosis of liver and its relation to prognosis in a tertiary care hospital - a retrospective study. International Journal of Contemporary Medicine Surgery and Radiology. 2019;4(2):B65B70.

\section{A B S T R A C T}

Introduction: Hepatic encephalopathy (H.E.) is a reversible syndrome of impaired brain function occurring in advanced liver failure patients. Common precipitating factors include gastrointestinal bleeding, infections, azotemia, constipation, electrolyte imbalance, and high protein diet. Patient outcome relies on early identification of the precipitating cause.

Material and methods: A retrospective, case record-based study was done using case records of all patients aged 18 years and above admitted with hepatic encephalopathy from January 2016 to December 2018. Hepatic encephalopathy was graded according to West Haven criteria and severity of liver cirrhosis using Child Turcotte Pugh scoring system. Precipitating factors, CTP score, HE stage were considered as outcome variables. Mortality was considered as explanatory variable. Data was entered in Microsoft excel and analysed with IBM SPSS version 22.

Results: The proportion of grade I, II, III, IV H.E. was 3.88\%, 36.89\%, 39.81\%, $19.42 \%$ respectively. Mortality was $17.48 \%$. Dehydration was the most common (78.64\%) precipitating factor followed by infections seen in $56.57 \%$ of the subjects (SBP-31\%, UTI-1.94\%, respiratory infections - 15.53\%), diuretics (46.6\%), hypokalemia (35.3\%), constipation (33\%) and G.I. bleeding (30\%). There was no significant association between mortality in HE with duration of disease, dehydration, SBP, respiratory infections, diuretics, malena.

Conclusions: Dehydration and infections were the most common precipitating factors in our study, although various factors play a role in precipitating hepatic encephalopathy. Early identification and treatment of precipitating factors and health education among cirrhotic patients, regarding precipitating factors are of paramount importance in the prevention and management of hepatic encephalopathy.

Keywords: Liver Cirrhosis, Encephalopathy, Neuropsychiatric Disorder, Precipitating factors, West Haven Criteria, Clinical Profile, Mortality, Child Turcotte Pugh Scoring System

\section{INTRODUCTION}

In developing countries like India, liver diseases continue to pose a significant health problem. The rise in the burden of chronic liver diseases and its complications has a huge impact on the economy. A serious neuropsychiatric disorder occurring in liver dysfunction patients in the absence of brain disease constitutes Hepatic encephalopathy. ${ }^{1}$ In the recently reported WHO (World Health Organization) data, 2.95\% of total deaths in India were caused by liver diseases deaths. ${ }^{2}$ India was ranked $63^{\text {rd }}$ in the world when age-adjusted death rates (22.93 per 100,000 of population) were calculated. ${ }^{2}$ Hepatic encephalopathy also known as portosystemic encephalopathy (PSE) is a reversible syndrome of impaired brain function occurring in advanced liver failure patients. ${ }^{3}$ It is associated with poor survival and a high risk of recurrence and even in its mildest form, health-related quality of life is reduced drastically. ${ }^{4}$ Subtle signs of $\mathrm{HE}$ are observed in nearly $70 \%$ of patients and overt hepatic encephalopathy occurs in about $30-45 \%$ of patients with cirrhosis. ${ }^{5}$ In chronic liver diseases, normally, ammonia is produced by bacteria in the gastrointestinal tract due to breakdown of amines, amino acids, purines, and urea and it is followed by metabolism and clearance by the liver. But in cirrhosis or advanced liver dysfunction, there is either a decrease in the number of functioning hepatocytes or portosystemic shunting, or both resulting in impaired ability of liver to detoxify toxins and hyperammonemia. HE is characterized by a spectrum of neuropsychiatric abnormalities resulting from the accumulation of neurotoxic substances in the bloodstream and ultimately building up in the brain. The results of correlation of ammonia levels with grade of HE have been contradicting. ${ }^{6,7}$ Most episodes of $\mathrm{HE}$ in patients with 


\begin{tabular}{|l|c|c|c|}
\hline Factor & 1 point & 2 points & 3 points \\
\hline Encephalopathy & None & Minimal & Advanced \\
\hline Bilirubin(mg/dl) & $<2$ & $2-3$ & $>3$ \\
\hline Albumin(g/dl) & $>3.5$ & $3.0-3.5$ & $<3$ \\
\hline Prothrombin Time (prolonged in sec or INR) & $<4$ sec or INR $<1.7$ & $4-6$ sec or INR 1.7-2.3 & $>6$ sec or INR $>2.3$ \\
\hline Ascites & None & Easily controlled & Poorly controlled \\
\hline Class A 5-6 points, Class B 7-9 points, Class C >10 points \\
\hline \multicolumn{2}{|c}{ Table-1: } \\
\hline
\end{tabular}

\begin{tabular}{|l|c|}
\hline Parameter & Summary \\
\hline Age(Mean \pm STD) & $49.58 \pm 12.26$ \\
\hline Gender (N (\%)) & $95(92.23 \%)$ \\
\hline Male & $8(7.77 \%)$ \\
\hline Female & $59(57.28 \%)$ \\
\hline Outcome (N (\%)) & $15(14.56 \%)$ \\
\hline Improved & $11(10.68 \%)$ \\
\hline Referred & $18(17.48 \%)$ \\
\hline DAMA & $1(0.97 \%)$ \\
\hline Death & $12(11.65 \%)$ \\
\hline Child Turcotte Pugh (CTP) score & $90(87.38 \%)$ \\
\hline A & \\
\hline B & $91(88.35 \%)$ \\
\hline C & $5(4.85 \%)$ \\
\hline Etiology & $3(2.91 \%)$ \\
\hline Alcohol & $2(1.94 \%)$ \\
\hline Hepatitis B & $1(0.97 \%)$ \\
\hline Alcohol/Hepatitis B & $1(0.97 \%)$ \\
\hline Cryptogenic & \\
\hline Hepatitis C & \\
\hline Others/Wilsons disease & \\
\hline Table-2: Descriptive analysis of baseline parameters in study \\
\hline \multicolumn{2}{|l|}{} \\
\hline
\end{tabular}

\begin{tabular}{|l|c|}
\hline Parameter N (\%) & Summary \\
\hline Dehydration & $81(78.64 \%)$ \\
\hline Spontaneous Bacterial Peritonitis (SBP) & $31(30.10 \%)$ \\
\hline Respiratory Infection & $16(15.53 \%)$ \\
\hline Urinary tract Infection (UTI) & $2(1.94 \%)$ \\
\hline Hematemesis & $16(15.53 \%)$ \\
\hline Malena & $15(14.56 \%)$ \\
\hline Constipation & $34(33.01 \%)$ \\
\hline Diarrhoea & $17(16.50 \%)$ \\
\hline Sedatives & $7(6.80 \%)$ \\
\hline Diuretics & $48(46.60 \%)$ \\
\hline Large volume paracentesis (LVP) & $1(0.97 \%)$ \\
\hline Hypokalaemia & $36(35.3 \%)$ \\
\hline Hyponatremia & $27(26.5 \%)$ \\
\hline Alcohol intake duration N (\%) & $8(8.33 \%)$ \\
\hline$<1$ week & $48(50.0 \%)$ \\
\hline 1 to 2 weeks & $5(5.21 \%)$ \\
\hline 2 to 4 weeks & $35(36.46 \%)$ \\
\hline$>4$ weeks & $62(60.19 \%)$ \\
\hline Onset of HE & $41(39.81 \%)$ \\
\hline New onset & \multicolumn{2}{|l}{} \\
\hline Recurrent & \\
\hline Table-4: Descriptive analysis of precipitating factors in study \\
\hline \multicolumn{2}{|l}{ population (N=103) } \\
\hline
\end{tabular}

\begin{tabular}{|l|l|}
\hline HE STAGE & Frequency (\%) \\
\hline I & $4(3.88 \%)$ \\
\hline II & $38(36.89 \%)$ \\
\hline III & $41(39.81 \%)$ \\
\hline IV & $20(19.42 \%)$ \\
\hline \multicolumn{2}{|c|}{ Table-3: Descriptive analysis of clinical parameters in study } \\
population ( $=103)$
\end{tabular}

cirrhosis are due to clinically apparent precipitating factors or the spontaneous development of portosystemic shunting. Common precipitating factors include gastrointestinal bleeding, infections, hypovolemia, azotemia, constipation, electrolyte imbalance, and high protein diet. Infections and GI bleeding were the most common precipitating factors documented in the literature..$^{8-11}$ The development of encephalopathy in patients with chronic liver disease is a poor prognostic sign but this complication can be managed in the vast majority of patients as hepatic encephalopathy in cirrhosis is usually reversible. ${ }^{12}$ However, patient outcome relies on early identification of the precipitating cause that caused deterioration. Hence, it is important to identify the precipitating cause and correct it early. In resource limited areas, most patients outcomes are poor and thought to be due to later stage presentation and limited treatment options. So,

this study was carried out with the objective of determining the clinical profile of hepatic encephalopathy in cirrhosis of liver and identifying precipitating factors and its correlation with the outcome.

\section{MATERIAL AND METHODS}

A retrospective, case record-based study was done using case records of all patients aged 18 years and above admitted with clinical signs and symptoms of cirrhosis of liver with hepatic encephalopathy from January 2016 to December 2018 after the approval of Institute ethics committee. Case records of patients of age less than 18 years who presented with acute fulminant hepatitis and non-cirrhotic portal hypertension, patients with intracranial lesions such as subdural hematoma, cerebral infarction, acute CNS infections, neuropsychiatric disorders, acute alcoholic intoxication and alcohol withdrawal state were excluded. A proforma was designed and used for data collection and entered in an Microsoft Excel sheet. Proforma included a detailed clinical history of the patient regarding the present and past illnesses, drug history particularly use of diuretics, sedatives or tranquilizers and past history of hospital admission, personal history about alcohol consumption and clinical examination findings 
like presence of fever, anaemia, jaundice, dehydration, asterixis, per abdominal and neurological findings. Hepatic encephalopathy is graded according to West Haven criteria. The severity of liver cirrhosis was assessed using Child Turcotte Pugh scoring system. (Table 1)

Relevant investigations like complete blood count, blood urea and creatinine, blood glucose, serum electrolytes, liver function test (LFT), coagulation profile, ultrasound of abdomen, HbsAg and Anti-HCV,UGI scopy, ascitic fluid analysis, treatment details and clinical outcome were also recorded.

\section{STATISTICAL ANALYSIS}

Precipitating factors, CTP score, HE STAGE...etc. were considered as outcome variables. Mortality was considered as explanatory variable. Age, gender were other variables. Descriptive analysis was carried out by mean and standard deviation for quantitative variables, frequency and proportion for categorical variables. The categorical data will be reported as percentage. Continuous data will be reported as mean. Categorical outcomes were compared between mortality using Chi square test. $\mathrm{P}$ value $<0.05$ was considered statistically significant. IBM SPSS version 22 was used for statistical analysis. ${ }^{13}$

\section{RESULTS}

A total of 103 subjects met the inclusion criteria and were included in the final analysis.

The mean age was 49.58 years $\pm 12.26 .95(92.23 \%)$ were males and remaining $8(7.77 \%)$ were females. Out of 103 patients

\begin{tabular}{|c|c|c|c|c|}
\hline \multirow[t]{2}{*}{ Parameter } & \multicolumn{2}{|c|}{ Mortality } & \multirow[t]{2}{*}{ Chi square } & \multirow[t]{2}{*}{ P-value } \\
\hline & Recovered & Expired & & \\
\hline \multicolumn{5}{|l|}{ CTP score } \\
\hline$A(N=1)$ & $1(100 \%)$ & $0(0 \%)$ & \multirow[t]{3}{*}{ * } & \multirow[t]{3}{*}{ * } \\
\hline $\mathrm{B}(\mathrm{N}=12)$ & $12(100 \%)$ & $0(0 \%)$ & & \\
\hline $\mathrm{C}(\mathrm{N}=90)$ & $72(80 \%)$ & $18(20 \%)$ & & \\
\hline \multicolumn{5}{|l|}{ ETIOLOGY } \\
\hline Alcohol & 75 (82.41\%) & $16(17.58 \%)$ & \multirow[t]{6}{*}{$*$} & \multirow[t]{6}{*}{ * } \\
\hline Hepatitis B & $4(80 \%)$ & $1(20 \%)$ & & \\
\hline Alcohol/Hepatitis B & $3(100 \%)$ & $0(0 \%)$ & & \\
\hline Cryptogenic & $2(100 \%)$ & $0(0 \%)$ & & \\
\hline Hepatitis C & $1(100 \%)$ & $0(0 \%)$ & & \\
\hline Others/Wilsons disease & $0(0 \%)$ & $1(100 \%)$ & & \\
\hline \multicolumn{5}{|l|}{ HE STAGE } \\
\hline I (N=4) & $4(100 \%)$ & $0(0 \%)$ & \multirow[t]{4}{*}{ * } & \multirow[t]{4}{*}{ * } \\
\hline $\mathrm{II}(\mathrm{N}=38)$ & $38(100 \%)$ & $0(0 \%)$ & & \\
\hline $\mathrm{III}(\mathrm{N}=41)$ & 32 (78.04\%) & $9(21.95 \%)$ & & \\
\hline $\mathrm{IV}(\mathrm{N}=20)$ & $11(55 \%)$ & $9(45 \%)$ & & \\
\hline \multicolumn{5}{|l|}{ Precipitating factors } \\
\hline Dehydration $(\mathrm{N}=81)$ & $66(81.48 \%)$ & $15(18.51 \%)$ & 0.286 & 0.593 \\
\hline $\mathrm{SBP}(\mathrm{N}=31)$ & 27 (87.09\%) & $4(12.90 \%)$ & 0.643 & 0.423 \\
\hline Respiratory infections(N=16) & $13(81.25 \%)$ & $3(18.75 \%)$ & 0.021 & 0.884 \\
\hline UTI(N=2) & $2(100 \%)$ & $0(0 \%)$ & $*$ & $*$ \\
\hline Hematemesis $(\mathrm{N}=16)$ & $9(56.25 \%)$ & $7(43.75 \%)$ & 9.067 & 0.003 \\
\hline Malena( $(\mathrm{N}=15)$ & $10(66.66 \%)$ & $5(33.33 \%)$ & 3.061 & 0.080 \\
\hline Constipation(N=34) & $31(91.17 \%)$ & $3(8.823 \%)$ & 2.635 & 0.105 \\
\hline Diarrhea(N=17) & $13(76.47 \%)$ & $4(23.52 \%)$ & 0.517 & 0.472 \\
\hline Sedatives( $\mathrm{N}=7)$ & $6(85.71 \%)$ & $1(14.28 \%)$ & 0.053 & 0.818 \\
\hline Diuretics $(\mathrm{N}=48)$ & $41(85.41 \%)$ & $7(14.58 \%)$ & 0.521 & 0.470 \\
\hline $\mathrm{LVP}(\mathrm{N}=1)$ & $1(100 \%)$ & $0(0 \%)$ & $*$ & $*$ \\
\hline Hypokalemia(N=36) & $28(77.77 \%)$ & $8(22.22 \%)$ & 0.801 & 0.371 \\
\hline Hyponatremia(N=27) & $22(81.48 \%)$ & $5(18.51 \%)$ & 0.019 & 0.890 \\
\hline \multicolumn{5}{|l|}{ Alcohol intake duration } \\
\hline$<1$ week $(\mathrm{N}=8)$ & $7(87.5 \%)$ & $1(12.5 \%)$ & \multirow[t]{4}{*}{10.483} & \multirow[t]{4}{*}{0.015} \\
\hline 1 to 2 weeks $(\mathrm{N}=48)$ & $38(79.16 \%)$ & $10(20.83 \%)$ & & \\
\hline 2 to 4 weeks $(\mathrm{N}=5)$ & $2(40 \%)$ & $3(60 \%)$ & & \\
\hline More than 4 weeks $(\mathrm{N}=35)$ & 33 (94.28\%) & $2(5.714 \%)$ & & \\
\hline \multicolumn{5}{|l|}{ Onset of $\mathrm{HE}$} \\
\hline New onset & $51(82.26 \%)$ & $11(17.74 \%)$ & \multirow[t]{2}{*}{0.008} & \multirow[t]{2}{*}{0.944} \\
\hline Recurrent & $34(82.93 \%)$ & $07(17.07 \%)$ & & \\
\hline
\end{tabular}




\begin{tabular}{|c|c|c|c|c|c|}
\hline Author & GIB & Constipation & Infection & Hypokalemia & Hyponatremia \\
\hline Current study $(\mathrm{N}=103)$ & $30 \%$ & $33 \%$ & $56.57 \%$ & $35.3 \%$ & $26.5 \%$ \\
\hline Tariq $\mathrm{M}$ et $\mathrm{a}^{11}(2009)(\mathrm{N}=200)$ & $29 \%$ & $30 \%$ & $19.5 \%$ & $4.5 \%$ & $1.5 \%$ \\
\hline Maqsood S et al $\left.\right|^{12}(2006)(\mathrm{N}=50)$ & $38 \%$ & $38 \%$ & $44 \%$ & - & - \\
\hline Nayak $M$ et al ${ }^{9}(2016)(\mathrm{N}=50)$ & $68 \%$ & $34 \%$ & $26 \%$ & $24 \%$ & $14 \%$ \\
\hline Kumar SKK et al ${ }^{10}(2017)(\mathrm{N}=76)$ & $47 \%$ & $53.3 \%$ & $22 \%$ & $40 \%$ & $42 \%$ \\
\hline Iqbal J et al ${ }^{14}$ (2016) (N=96) & $44 \%$ & $9 \%$ & $38 \%$ & - & - \\
\hline
\end{tabular}

59(57.28\%) recovered and were discharged, 11(10.68\%) got discharge against medical advice and 18(17.48\%) expired and all were males. According to Child Pugh Score, 90(87.38\%) were in Class C, 12(11.65\%) were in Class B and remaining $1(0.97 \%)$ were in Class A. In this study the commonest cause of cirrhosis was found to be alcoholism 91(88.35\%), followed by Hepatitis B 5(4.85\%), alcoholic with hepatitis B 3(2.91\%), cryptogenic 2(1.94\%) and hepatitis C 1 (0.97\%) (table-2).

Among the precipitating factors the most common was dehydration $81(78.64 \%)$, followed by diuretics $48(46.60 \%)$, hypokalemia 36(35.3\%), constipation 34(33.01\%), SBP $31(30.10 \%)$ and UGI bleed 31 (30.09\%). Among the study population in $8(8.33 \%)$ of patients the time of alcohol intake was less than 1 week, $48(50.0 \%)$ had between 1 to 2 weeks, 5(5.21\%) had 2 to 4 weeks and 35(36.46\%) had alcohol intake duration more than 4 weeks. In the study population 62(60.19\%) people had new onset of HE and remaining 41(39.81\%) had recurrent onset of HE (Table 4).

Among all precipitating factors there was significant association between mortality in $\mathrm{HE}$ and haematemesis. All patients who expired belonged to class $\mathrm{C}$ according to Child Pugh score. Mortality rate of patients in class C is $20 \%$. The difference in the proportion of duration of disease between mortality was statistically not significant $(\mathrm{P}$ value 0.69 ) (table-5).

\section{DISCUSSION}

Hepatic encephalopathy (HE) is a major complication of liver cirrhosis that leads to significant morbidity and mortality. Although the exact pathogenic mechanism is yet to be determined, in majority of patients with $\mathrm{HE}$, a clearly definable precipitating factors can be identified and reversal or control of these factors is the key step in the management. In the present study, a total of 103 patients with cirrhosis of liver presenting with HE were included. Their clinical presentation, precipitating factors and their outcomes were recorded and analyzed. $60.19 \%$ had new onset H.E. while $39.81 \%$ had recurrent H.E. Clinically $39.81 \%$ presented with grade III H.E. while $36.89 \%$ presented with grade II H.E. $19.42 \%$ had grade IV H.E. at presentation compared to only $3.88 \%$ with grade I H.E. Dehydration was the most common (78.64\%) precipitating factor followed by infections seen in $56.57 \%$ of the subjects (SBP-31\%, UTI-1.94\%, Respiratory infections - 15.53\%), diuretics (46.6\%), hypokalemia (35.3\%), constipation (33\%) and G.I. bleeding in 30\% of the subjects (hematemesis - 15.53\%, malena-14.56\%). There was significant association between mortality in $\mathrm{HE}$ and haematemesis in our study. But there was no significant association between mortality in $\mathrm{HE}$ with duration of disease, dehydration, infections and diuretics. In this study, majority of the study subjects were males (92.23\%). The male preponderance is explained by the patterns of alcohol consumption in males. Similar male dominance was also reported by Iqbal J et al ${ }^{14}$ and Kumar SKK et al. ${ }^{10}$ The mean age of the subjects was 51.25 years in the study by Kumar SKK et $\mathrm{al}^{10}$ similar to our study $(49.58 \pm 12.26)$ years. In our study, most of the subjects (56.31\%) were aged between 41 to 60 years with the mean age of the study population at $49.58( \pm 12.26)$ years. The mean age of the subjects was also 47 years in the study by Raphael KC et al..$^{15} 45.63 \%$ of our study subjects stayed in the hospital between 1 week to 3 weeks. Similarly Iqbal J et a $1^{14}$ also reported a mean hospital stay duration of 11 days in their study. The mortality in our study was $17.48 \% .57 .28 \%$ recovered and were discharged. $10.68 \%$ got discharged against medical advice and $14.56 \%$ were referred. Similar to our study, Iqbal J et a ${ }^{14}$ reported a mortality of $11.4 \%$ in their study. The mortality rate was higher (23\%) than our study in the study done by Devrajani BR et $\mathrm{al}^{8}$ in Hyderabad. This higher mortality in their study compared to our study can be attributed to the difference in the severity of $\mathrm{HE}$ between the studies. In their study $80 \%$ had grade IV H.E. compared to only $19.42 \%$ at presentation in our study. The West Haven Criteria categorizes HE into 4 stages. Clinically $39.81 \%$ presented with grade III H.E. while $36.89 \%$ presented with grade II H.E. in our study with only $3.88 \%$ presenting with grade I H.E. In the study by Nayak $\mathrm{M}$ et $\mathrm{al}^{9}$, majority of the patients had higher grades of encephalopathy with $36 \%$ in grade IV, $30 \%$ in grade III, $10 \%$ in grade II, while $24 \%$ had grade I HE. In the study by Kumar SKK et $\mathrm{al}^{10}$ done in kerala, they also observed that most of the subjects had Grade 2 and $3 \mathrm{HE}$. With regards to severity of cirrhosis assessed by CTP scores, $87.38 \%$ of our study subjects fell under class $\mathrm{C}$. In the study by Nayak $\mathrm{M}$ et $\mathrm{al}^{9}$ also, majority (60\%) were in Class $\mathrm{C}$ followed by $24 \%$ in Class A and only $16 \%$ in Class B. Similarly Raphael KC et $\mathrm{al}^{15}$ also reported that $77.3 \%$ of their subjects had class $\mathrm{C}$ CTP score.

Hepatic encephalopathy (HE) is a major complication of endstage liver disease and acute liver failure. Overt $\mathrm{HE}(\mathrm{OHE})$ occurs in at least $30 \%$ to $45 \%$ of patients with cirrhosis as well as in $10 \%$ to $50 \%$ of patients who have undergone transjugular intrahepatic portosystemic shunt, and is one of the defining characteristics of acute liver failure. ${ }^{16}$ The most common cause of cirrhosis of liver in our study was alcohol (88.35\%). $4.85 \%$ of subjects had Hepatitis B while $0.97 \%$ had Hepatitis $\mathrm{C}$ infection and $2.9 \%$ had Hepatitis B infection besides being alcoholic. The most common cause in the study by Nayak M et $\mathrm{al}^{9}$ was also alcohol (76\%) followed by HBV (16\%) and 
$\mathrm{HCV}$ (4\%) being the other leading causes. HE in cirrhosis occurs mainly due to clinically apparent precipitating factors or the spontaneous development of portosystemic shunting. Common precipitating factors include gastrointestinal bleeding, infections, hypovolemia, azotemia, constipation, electrolyte imbalance, and high protein diet. ${ }^{8-11}$ But it is usually reversible ${ }^{12}$ and hence arises the need for identifying the precipitating cause and correcting it early.

Dehydration was the most common (78.64\%) precipitating factor in our study followed by infections (56.57\%), diuretic use (46.6\%). But Nayak $\mathrm{M}$ et al ${ }^{9}$ in their study reported that the most common precipitating factor was hematemesis (38\%) followed by malena (30\%) and constipation (34\%). They did not include dehydration as a precipitating factor in their study. Similarly, in our study, constipation was the precipitating factor in $33 \%$ of subjects and hematemesis was the precipitating factor in $15.53 \%$ followed by malena in $14.56 \%$ of subjects. But in their study infections were the precipitating factors in only $26 \%$ of the subjects. Tariq $\mathrm{M}$ et $\mathrm{al}^{11}$ in their study observed that amongst the precipitating factors, 30\% had constipation, 29\% had upper gastrointestinal bleed (GIB), 8\% had spontaneous bacterial peritonitis (SBP), $19.5 \%$ had urinary tract infection (UTI) and $2.5 \%$ had lower respiratory infection. But in our study, $30.1 \%$ had SBP and $15.53 \%$ had respiratory infections as the precipitating factor. Infections played a significant role in precipitating H.E. in our study compared to their study. Maqsood S et $\mathrm{al}^{12}$ in their study also observed that infection (44\%), gastrointestinal bleeding (38\%) and constipation (38\%) were the major precipitating factors of H.E. in their study. Iqbal $\mathrm{J}$ et $\mathrm{al}{ }^{14}$ in their study observed that gastrointestinal bleed was the most common precipitating factor (44\%) followed by infections(38\%). Kumar SKK et $\mathrm{al}^{10}$ in their study observed that the common precipitants of HE were GI bleed (47\%), dyselectrolemia, constipation (53.3\%) and infections (22\%). Among these precipitants a statistically significant association for a worse outcome was seen only with infection in their study. But there was significant association between mortality in $\mathrm{HE}$ and haematemesis in our study. There was no significant association between mortality in $\mathrm{HE}$ with duration of disease, dehydration, SBP, respiratory infections, diuretics, malena in our study. Iqbal $\mathrm{J}$ et $\mathrm{a} \mathrm{l}^{14}$ similarly in their study, they also observed no correlation between the various precipitating factors and mortality. Most of the patients in our study had recent alcohol intake of less than 1 week before the episode of hepatic encephalopathy. About (51.23 $\%)$ of patients with recurrent $\mathrm{HE}$ had recent alcohol intake (table-6).

\section{CONCLUSION}

Even in its mildest form, HE reduces health-related quality of life and is a risk factor for bouts of severe HE. In the presence of the precipitating factors, the neurological deficits are usually completely reversible upon their correction and the prognosis is better if the precipitant can be treated. Dehydration was the most common (78.64\%) precipitating factor in this study. It was followed by infections (56.57\%), diuretics (46.6\%), hypokalemia (35.3\%), constipation (33\%) and G.I. bleeding (30\%) as observed in other studies. The mortality was $17.48 \%$ in this study. Among all precipitating factors there was significant association between mortality in $\mathrm{HE}$ and haematemesis in our study. But our study was limited by its smaller sample size and the study sample which included only the hospitalised subjects. It can be concluded from the results of our study that in a developing country like India, where the prevalence of alcoholism and chronic liver disease is high, H.E.is not uncommon. Since H.E. is completely reversible, much emphasis is put on identifying and treating the precipitating factor at the earliest.

\section{REFERENCES}

1. Butterworth RF. Neurosteroids in hepatic encephalopathy: Novel insights and new therapeutic opportunities. J Steroid Biochem Mol Biol. 2016;160(1):94-7.

2. World Health Rankings.World Health Organization 2017. http://www.worldlifeexpectancy.com/india-liverdisease. Accessed on 10 July 2018.

3. Ferenci P. Hepatic encephalopathy. Gastroenterology report. 2017;5(2):138-47.

4. Bianchi G, Giovagnoli M, Sasdelli AS, Marchesini G. Hepatic encephalopathy and health-related quality of life. Clin Liver Dis. 2012;16(1):159-70.

5. Poordad FF. Review article: the burden of hepatic encephalopathy. Aliment Pharmacol Ther. 2007;25 Suppl 1:3-9.

6. Qureshi MO, Khokhar N, Shafqat F. Ammonia levels and the severity of hepatic encephalopathy. J Coll Physicians Surg Pak. 2014;24(3):160-3.

7. Hadjihambi A, Arias N, Sheikh M, Jalan R. Hepatic encephalopathy: a critical current review. Hepatology international. 2017;12(Suppl 1):135-47.

8. Devrajani BR, Shah SZ, Devrajani T, Kumar D. Precipitating factors of hepatic encephalopathy at a tertiary care hospital Jamshoro, Hyderabad. J Pak Med Assoc. 2009;59(10):683-6.

9. Nayak M, Anubhaw N, Nayak R. Incidence of Hepatic Encephalopathy in Cirrhosis of Liver. IJCMR. 2016;3(12):3528-32.

10. Kumar SKK, Sarin SM, Valliyot B, Joy V, Beevi K, Balakrishnan S. Study to assess the changing pattern of clinical profile and determine the prognosis in hepatic encephalopathy. Int J Res Med Sci. 2017;5(2):424-8.

11. Tariq M, Iqbal S, ullah Khan N, Basri R. Precipitating factors of hepatic Encephalopathy. Rawal Medical Journal. 2009;34(1):95-7.

12. Maqsood S, Saleem A, Iqbal A, Butt JA. Precipitating factors of hepatic encephalopathy: experience at Pakistan Institute of Medical Sciences Islamabad. J Ayub Med Coll Abbottabad. 2006;18(4):58-62.

13. IBM Corp. Released 2013. IBM SPSS Statistics for Windows, Version 22.0. Armonk, NY: IBM Corp.

14. Iqbal J, Parvez MA, Alam MM. Analysis of Identifiable Risk Factors Precipitating Acute Encephalopathy in Chronic Liver Disease, At PNS Shifa Karachi. APMC. 2016;10(4):222-7.

15. Raphael KC, Matuja SS, Shen NT, Liwa AC, Jaka H. Hepatic Encephalopathy; Prevalence, Precipitating Factors and Challenges of Management in a ResourceLimited Setting.J Gastrointest Dig Syst. 2016;6(3):441. 
16. NeSmith M, Ahn J, Flamm SL. Contemporary Understanding and Management of Overt and Covert Hepatic Encephalopathy. Gastroenterol hepatol. 2016;12(2):91-100.

Source of Support: Nil; Conflict of Interest: None

Submitted: 01-05-2019; Accepted: 21-05-2019; Published online: 03-06-2019 